\title{
Editorial
}

\section{Increasing transparency in the British Journal of Nutrition}

Keen readers of the $B J N$ will have noticed the recent appearance of 'conflict of interest' statements and of more complete descriptions of the contribution of each author to the publication. I have introduced these innovations in order to increase the transparency of the articles that we publish in the $B J N$; further strategies to increase accuracy, transparency and accountability of papers published in the journal will follow in order to encourage a climate of intellectual honesty and to decrease the risk of misconduct. In particular, the journal will follow as closely as possible the recommendations and guidelines of the Committee on Publishing Ethics (COPE) ${ }^{(1)}$ and of the International Committee of Medical Journal Editors $(\text { ICMJE })^{(2)}$. COPE and ICMJE have made available a range of guidelines aimed at establishing best practice in scientific publishing. These include guidelines for authors and for the conduct of reviewers, editorial boards and editors. Many of the guidelines are already followed by the $B J N$, but others are not yet fully in place.

I believe that the $B J N$ has in place a transparent peerreview process and one that treats authors fairly whilst maintaining a high standard of scientific rigour. In most cases manuscripts are seen by two reviewers. In general, the identity of these peer reviewers has been hidden from authors, since this allows the former to be frank in their remarks without fear of prejudice. The $B J N$ will continue this practice. However, to be fair to authors and to ease the burden on the peer-review process, authors are encouraged to suggest potential reviewers and where this is done we have frequently used at least one of those suggested. Clearly, authors suggest the names of potential reviewers who they suspect will be kindly disposed towards them and their work. The view from 'the inside' of the process is that this is not always the case! One of our sister journals (Public Health Nutrition) anonymises manuscripts going for peer review by removing details of authors and their affiliations. The aim of course is to reduce bias (one way or the other) by reviewers and I am sure that this does happen, but many expert reviewers can easily and accurately guess the origin of a piece of work according to the nature of the experiments done, the models used, the writing and presentation style and the literature cited. I currently have no plans to introduce anonymity of the origin of manuscripts being reviewed for the $B J N$. My view is that the majority of the many hundreds of reviewers used by the $B J N$ each year carry out their task in a professional and unbiased manner. Manuscripts submitted to the $B J N$ are also reviewed by a member of the Editorial Board, providing a third opinion to the individual who makes the final decision on the manuscript (myself or one of the Deputy Editors). The majority of the time this process works well and I have, on occasion, received letters from authors thanking me for the fairness, professionalism and rigour of our peer-review process; enlightened authors see that by responding appropriately to well-founded criticisms of their manuscript, it is improved. Of course the $B J N$ receives many more manuscripts than it can publish, and thus the most common outcome for a manuscript is rejection. Clearly this is neither desired nor usually anticipated by authors. Because of this we strive to make it clear to authors, from the comments that they receive, why their manuscript has been rejected, and to transmit the decision to them in a courteous and professional manner.

The introduction of conflict of interest statements and of declarations by authors of their contribution to the article stem from my desire to increase the transparency of the articles published in the $B J N$ and to encourage honesty on the part of authors. The Vancouver guidelines on which contributions determine authorship, and which do not, are clear and may be found elsewhere ${ }^{(2)}$. The question of conflict of interest is rather less clear to authors but is dealt with by both COPE and $\operatorname{ICMJE}^{(1,2)}$. A conflict of interest is where an author (or a reviewer or an editor) has an interest that is not fully apparent and that may influence their judgments on what is published. The interest may be personal, commercial, political, academic or financial. Financial interests may include employment, research funding, stock, share or patent ownership, consultancies, or payment for lectures, travel or advice. Authors should be aware that inaccurate or false declarations of conflict of interest are considered by COPE, and by the $B J N$, to be serious breaches of publishing ethics.

The links between nutritional scientists and industry have probably never been stronger than at present, and so the scope for conflicts of interest is great. Academic institutions strongly encourage their scientists to form links with, and to seek funding from, industry and to commercialise their discoveries. Traditional non-commercial funders have developed schemes that link academic researchers with industry, so sharing the financial burden of research. An example of such a scheme in the UK is the so-called Agri-Food LINK programme where $50 \%$ of the funding for a research programme is from a source such as the Biotechnology and Biological Sciences Research Council and $50 \%$ from one or more industrial partners. Similar schemes exist for funding graduate students. In some instances a research grant is more likely to be funded if industry is involved than if there is no industrial collaboration. Funding from the European Commission for nutrition research practically has a requirement for 
the involvement of industry, both large and small. Such funding programmes are, of course, designed to promote innovation and to contribute to increased competitiveness of industry and wealth creation. Nevertheless they act to strongly align academic researchers with the world of commerce. Such an alignment will only increase over the next few years. The emergence of more dietary supplements, natural products, functional foods and specialised nutritional products and a desire to examine the efficacy and mechanisms of action of these, perhaps linked to developing marketing opportunities or to a requirement for substantiation of claims, will greatly increase industrial funding of, and involvement in, nutritional research. Industry may make other financial contributions to researchers: scientists may be paid to travel to and to speak at symposia arranged by industry or they may act as consultants or sit on advisory boards. Again it seems likely that these sorts of activities will increase as the food industry becomes more akin to the pharmaceutical industry in its practices. A recent article in the $B J N$ examined academic-industry partnerships with reference to nutrition research and provides some thoughts on how such relationships can be developed without the independence of academic researchers being threatened ${ }^{(3)}$. Nevertheless, it is apparent that the opportunities for loss of independence and for author bias will increase. It is only by declaring their conflicts that authors can make it clear to readers the interests they have that may influence the content of their article. To put it simply: the $B J N$ requires its authors to be honest, open and responsible.

\section{References}

1. Committee on Publishing Ethics (2003) Guidelines on Good Publication and the Code of Conduct. http://www.publicationethics. org.uk/guidelines

2. International Committee of Medical Journal Editors (2007) Uniform Requirements for Manuscripts Submitted to Biomedical Journals: Writing and Editing for Biomedical Publication. http://www.icmje.org/

3. Uauy R (2007) Academic-industry partnerships in addressing nutrition - [infection-immunity-inflammation] interactions. Br J Nutr 98, S17-S23.

Philip C. Calder Editor-in-Chief

School of Medicine University of Southampton Institute of Developmental Sciences Building MP887 Southampton General Hospital

Tremona Road

Southampton SO16 6YD

$U K$

email pcc@soton.ac.uk doi: 10.1017/S0007114507894451 